\title{
INTEGRATING COLLABORATIVE PROBLEM STRUCTURING TECHNIQUES AND THE ANALYTIC HIERARCHY PROCESS: THE CASE OF THE NEW REGIONAL TRANSPORTATION PLAN FOR 2050 IN THE PIEDMONT REGION
}

\begin{abstract}
Keywords: objectives elicitation, structuring, focus groups

\section{Introduction}

Scientific research has demonstrated that the identification of fundamental objectives is not an easy task and that without support people are often aware of only half of the objectives that turn out to be relevant to them (Bond et al., 2008). The research question driving this study is: "how to integrate value-focused thinking and the AHP for public policy making?".
\end{abstract}

\section{Literature Review}

There is an increasing interest towards the use of problem structuring methods for the generation of objectives. This work experiments the use of Keeney's devices (Keeney, 1992) in the problem structuring phase of the AHP.

\section{Hypotheses/Objectives}

The objective of the study is to support the Piedmont Regional Authority in the identification and prioritization of the relevant objectives for the new Regional Transportation Plan for 2050.

\section{Research Design/Methodology}

The process consisted in the development of three subsequent focus groups with real actors, all with different competencies and backgrounds, from the Transportation Directorate of the Regional Authority. A facilitated modelling approach has been used allowing for real time discussion of the results.

\section{Data/Model Analysis}

Given the limited availability of economic resources, the AHP has been used to draw recommendation for the development and prioritization of strategic actions within the new Plan.

\section{Limitations}

The high number of pairwise comparison questions has been dealt with by proposing to the actors only the subset of strictly necessary questions. 


\section{Conclusions}

The main contribution stems from the development of an effective collaborative framework which allowed to overcome heterogeneity of points of view and foster an active contribution of the participants.

\section{Key References}

Bond, S., Carlson, K., Keeney, R. (2008). Generating Objectives: Can Decision Makers Articulate What They Want?"Management Science, 56-70

Keeney, R.L. (1992). Value focused thinking. Harvard university press: Cambridge. 